\title{
Nanocomposite Magnetite-Kaolin for Rh Preconcentration and Determination by Electrothermal Atomic Absorption Spectrometry
}

\author{
Mai FurukaWa, ${ }^{* \dagger}$ Ikki TAteISHI,** Hideyuki Katsumata,* Risako KuSunOKI,* and Satoshi KaneCO*,** \\ *Department of Chemistry for Materials, Graduate School of Engineering, Mie University, Tsu, Mie 514-8507, \\ Japan \\ **Global Environment Center for Education \& Research, Mie University, Tsu, Mie 514-8507, Japan
}

\begin{abstract}
A preconcentration technique with a magnetite-kaolin adsorbent capable of magnetic separation was developed for the determination of rhodium in environmental samples. The magnetite-kaolin nanocomposite was prepared for the preconcentration of rhodium in an aqueous solution prior to an electrothermal atomic absorption spectrometric determination. The detection limit $(3 S / N)$ of rhodium was $16 \mathrm{pg} \mathrm{mL}^{-1}$ under the optimum conditions. Even though matrix elements existed in $10^{3}$ fold excess in aqueous solution, the rhodium adsorption could be not affected by the matrix. The present method could be applied to the determination of $\mathrm{Rh}$ in an aqueous solution. The advantages are easy preparation of the adsorbent and fast magnetic separation.
\end{abstract}

Keywords Preconcentration, magnetic kaolin, rhodium, ETAAS, water

(Received September 5, 2019; Accepted November 15, 2019; Advance Publication Released Online by J-STAGE November 29, 2019)

\section{Introduction}

Until now, Rh (rhodium) has been widely employed as a raw product of plating in electronic instruments and as a catalytic converter for the purpose of controlling automotive emissions. ${ }^{1}$ As a consequence, $\mathrm{Rh}$ has been extendedly distributed into the environmental field. Hence, it is necessary to develop the sensitive monitoring techniques of rhodium in environmental samples. ${ }^{1}$

Recently, the analysis of rhodium by inductively coupled plasma optical emission spectrometry (ICP-OES) and inductively coupled plasma mass spectrometry (ICP-MS) has been conducted. $^{2}$ These techniques are highly sensitive, though the instrumentation is more complex and costly. Electrothermal atomic absorption spectrometry (ETAAS), namely, graphite furnace atomic absorption spectrometry (GFAAS) is very convenient and in much more general use. ${ }^{3}$ Since the detection limit of $\mathrm{Rh}$ for ETAAS is not superior, ${ }^{3}$ a preconcentration method for rhodium is needed for determining $\mathrm{Rh}$ for an ultratrace concentration in the environmental sample. ${ }^{4}$ Furthermore, a preliminary separation process is often required because of matrix interferences. Techniques containing coprecipitation, liquid-liquid extraction, electrolytic deposition (electrodeposition), electrophortetic separation, sorption, adsorption and solid-phase extraction have been applied to the separation and preconcentration of trace $\mathrm{Rh}$ in various samples. ${ }^{4}$

Kaolin $\left(\mathrm{Al}_{2} \mathrm{Si}_{2} \mathrm{O}_{5}(\mathrm{OH})_{4}\right.$ or $\left.\mathrm{Al}_{2} \mathrm{O}_{3} \cdot 2 \mathrm{SiO}_{2} \cdot 2 \mathrm{H}_{2} \mathrm{O}\right)$ is abundant in nature and is available. It is a layered silicate consisting of platelets connected by hydrogen bonding. Kaolin has recently been applied to many industrial processes owing to its good

† To whom correspondence should be addressed.

E-mail: chem.mie-u.ac.jp bonding ability and thermal stability. The removal of heavy metals from aqueous solution by kaolin has been reported by Yavuz et al., ${ }^{5}$ and it was found from the results that kaolinite has better absorption ability for $\mathrm{Cu}, \mathrm{Co}, \mathrm{Mn}$ and $\mathrm{Ni}$. Because the adsorption materials are generally powder forms, it is difficult to separate the solid from a liquid phase. In order to solve this problem, magnetic separation using an external magnetic field has attracted great attention due to high separation efficiency, a shorter time and less energy consumption. ${ }^{6}$ Although many works has been carried out using the magnetic separation method and kaolin separation, ${ }^{6,7}$ there is little information on the preconcentration technique for rhodium with magnetic kaolin. The present work focuses on the determination of $\mathrm{Rh}$ in environmental samples by ETAAS combined with the preconcentration technique with magnetic kaolin.

\section{Experimental}

\section{Reagents and chemicals}

All of the chemical reagents were of analytical grade, and used without further purification. Ultrapure water (18.2 M $\Omega$ $\mathrm{cm})$ was obtained from an Advantec ultrapure water system (CPW-102; Tokyo, Japan). All solutions were prepared with ultrapure (deionized) water. An aqueous standard solution of rhodium was prepared by diluting a $1 \mathrm{mg} \mathrm{mL}^{-1}$ stock solution obtained from KANTO CHEMICAL Co., Inc. (Tokyo, Japan). Iron salts $\left(\mathrm{FeCl}_{2} \cdot 4 \mathrm{H}_{2} \mathrm{O}\right.$ and $\left.\mathrm{FeCl}_{3}\right)$ were obtained from FUJIFILM Wako Pure Chemical Corp. (Osaka, Japan). Matrix solutions of $\mathrm{Ca}, \mathrm{Cu}, \mathrm{K}, \mathrm{Mg}, \mathrm{Mn}, \mathrm{Ni}$ and $\mathrm{Pb}$ were prepared by the dissolution of nitrates and hydrochlorides. Kaolin was purchased from FUJIFILM Wako Pure Chemical Corp. (Osaka, Japan). 


\section{Preparation of magnetic $\mathrm{Fe}_{3} \mathrm{O}_{4} /$ kaolin}

Kaolin- $\mathrm{Fe}_{3} \mathrm{O}_{4}$ composites were synthesized according to the literature with some modification. ${ }^{8}$ A suspension of $0.5 \mathrm{~g}$ kaolin of a $200-\mathrm{mL}$ solution including $0.32 \mathrm{~g} \mathrm{FeCl}_{3}$ and $0.2 \mathrm{~g}$ $\mathrm{FeCl}_{2} \cdot 4 \mathrm{H}_{2} \mathrm{O}$ was heated at $80^{\circ} \mathrm{C}$ for $80 \mathrm{~min}$. Then, $25 \mathrm{~mL}$ of $4 \mathrm{~mol} \mathrm{~L}^{-1} \mathrm{NaOH}$ was added dropwise to fabricate iron oxide. The composites were aged at $100^{\circ} \mathrm{C}$ during $90 \mathrm{~min}$, and then were washed 3 times with pure water. The obtained composites were dried under vacuum conditions for $24 \mathrm{~h}$. The characterization of kaolin- $\mathrm{Fe}_{3} \mathrm{O}_{4}$ composites are shown in Figs. S1 to S4 and Tables S1 to S3 (Supporting Information).

\section{Preconcentration procedure}

The initial $\mathrm{pH}$ of the solution $(100 \mathrm{~mL})$ was adjusted to 5 using $0.1 \mathrm{~mol} \mathrm{~L}^{-1} \mathrm{HNO}_{3}$ and $0.1 \mathrm{~mol} \mathrm{~L} \mathrm{~L}{ }^{-1} \mathrm{NaOH}$. Then, $50 \mathrm{mg}$ of magnetic kaolin was added into the analyzed solution, and the magnetic kaolin nanopowders were sonicated for $7 \mathrm{~min}$ for dispersing the adsorbent using an ultrasonic cleaner (SIBATA SCIENTIFIC TECHNOLOGY Ltd., SUP-10, 100 W, Saitama, Japan). Next, the magnetic adsorbent was magnetically removed from the sample solution using a powerful magnet. After decantation of the supernatant solution, the obtained adsorbent was washed with $1.0 \mathrm{~mL}$ of a $0.5 \mathrm{~mol} \mathrm{~L}^{-1} \mathrm{HNO}_{3}$ solution in order to desorb the $\mathrm{Rh}$ ions. The concentrated solution for $\mathrm{Rh}$ was obtained by the magnetic removal of adsorbents with a powerful magnet.

\section{Analysis by ETAAS}

An analysis for rhodium determination was carried out with a SHIMADZU AA-7000 equipped with an electrothermal graphite atomizer (GFA-7000A), an auto-sampler (ASC-7000) and a deuterium lamp background corrector (Kyoto, Japan). A Rh hallow cathode lamp was carried out for absorbance measurements at a wavelength of $343.5 \mathrm{~nm}$, and was operated at $10 \mathrm{~mA}$ with a spectral bandwidth of $0.7 \mathrm{~nm}$. The peak-height absorbance mode was adapted. Pyrolytically coated graphite tubes were used. Argon was used as a sheathing gas, and the internal Ar gas flow in the graphite atomizer was interrupted in the atomization step. The furnace temperature programs are described in Table S4 in Supporting Information. The analytical data were the average values obtained with more than three samples.

\section{Results and Discussion}

\section{Choice of kaolin}

In order to confirm the higher adsorption affinity for kaolin, various magnetic adsorbents containing $\mathrm{Fe}_{3} \mathrm{O}_{4} /$ kaolin, $\mathrm{Fe}_{3} \mathrm{O}_{4} / \mathrm{Al}_{2} \mathrm{O}_{3}$, $\mathrm{Fe}_{3} \mathrm{O}_{4} / \mathrm{TiO}_{2}$ and $\mathrm{Fe}_{3} \mathrm{O}_{4} /$ halloysite nanoclay were fabricated for the preconcentration of $\mathrm{Rh}$. Photographs of the eluents after the preconcentration of rhodium using different magnetic adsorbents are illustrated in Fig. S5 in Supporting Information. The colors of eluents with magnetic $\mathrm{Al}_{2} \mathrm{O}_{3}, \mathrm{TiO}_{2}$ and halloysite nanoclay were not transparent, and these phenomena mean peeling of $\mathrm{Fe}_{3} \mathrm{O}_{4}$, and the dissolution of iron may occur owing to worse adhesion. However, in the case of $\mathrm{Fe}_{2} \mathrm{O}_{3} / \mathrm{kaolin}$, the color was transparent. Furthermore, the maximum enrichment factor was observed with the adsorption of magnetic kaolin. Hence, in the present work, the optimum conditions for the preconcentration of $\mathrm{Rh}$ was explored with magnetic kaolin.

\section{Effect of aging processes}

Since the aging (heating) temperatures during the fabrication of adsorbent affected the surface color of magnetic kaolin, their

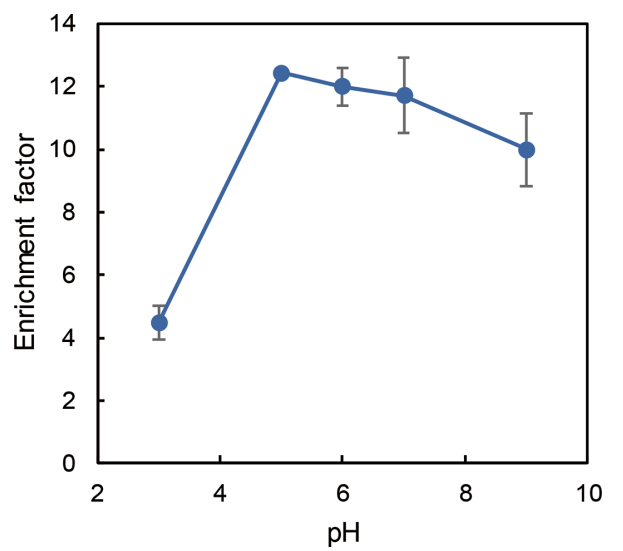

Fig. 1 Effect of the solution $\mathrm{pH}$ on the enrichment factor of $\mathrm{Rh}$. Sample, Rh $1 \mathrm{ng} \mathrm{mL}^{-1}(100 \mathrm{~mL})$; adsorbent, magnetite/kaolin $50 \mathrm{mg}$; eluent, $\mathrm{HNO}_{3} 0.1 \mathrm{~mol} \mathrm{~L}^{-1}(2 \mathrm{~mL})$.

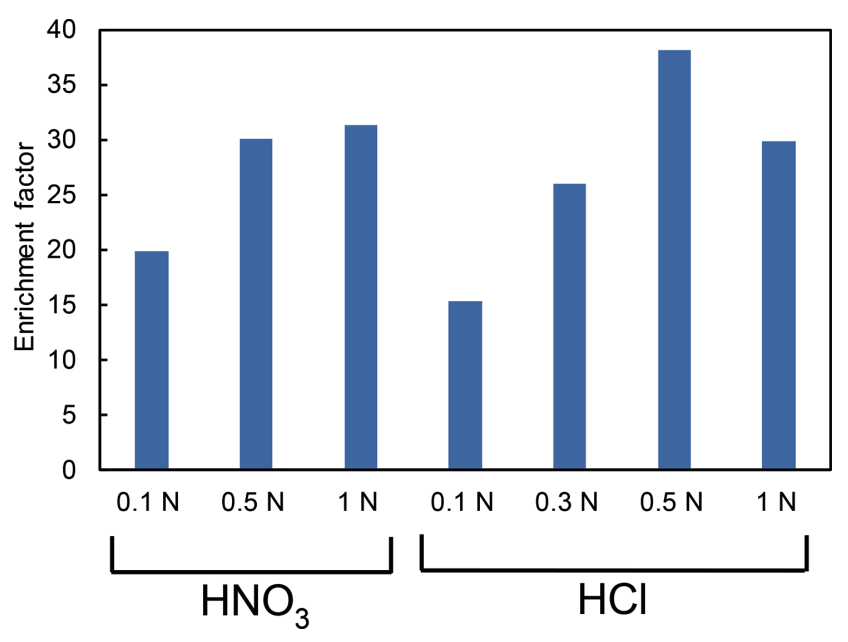

Fig. 2 Effect of eluent type on the enrichment factor of Rh. Sample, $\mathrm{Rh} 1 \mathrm{ng} \mathrm{mL} \mathrm{m}^{-1}(100 \mathrm{~mL})$; solution $\mathrm{pH}, 5$; adsorbent, magnetite/kaolin $50 \mathrm{mg}$.

surface conditions for the magnetic kaolin may be dependent on the dry processes. Therefore, the effect of the heating (aging) conditions on the enrichment factor of rhodium was studied. The aging temperatures were tested in the range of $25^{\circ} \mathrm{C}$ to $200^{\circ} \mathrm{C}$. The results are shown in Figs. S6 and S7 (Supporting Information). The aging temperatures and times could affect the enrichment factors for the preconcentration of $\mathrm{Rh}$. The maximal enrichment factor was observed with aging at $100^{\circ} \mathrm{C}$ for $90 \mathrm{~min}$. Therefore, these aging conditions were used for the fabrication of magnetic kaolin.

\section{Effect of the $p H$}

It has been reported that deposition, sorption and adsorption methods can be frequently effected by the solution $\mathrm{pH} \cdot \cdot^{9-11}$ Therefore, the influence of the solution $\mathrm{pH}$ on the enrichment factor of analyte was investigated in the range of 3 to 9 when the other parameters were kept constant. The results are shown in Fig. 1. The enrichment factor of Rh increased gradually as the solution $\mathrm{pH}$ decreased from 9 to 5 . The maximum enrichment factor was obtained at $\mathrm{pH} 5$. At a lower $\mathrm{pH}(<5.0)$, there was competition between $\mathrm{H}^{+}$ions and $\mathrm{Rh}$ ions to occupy the active 


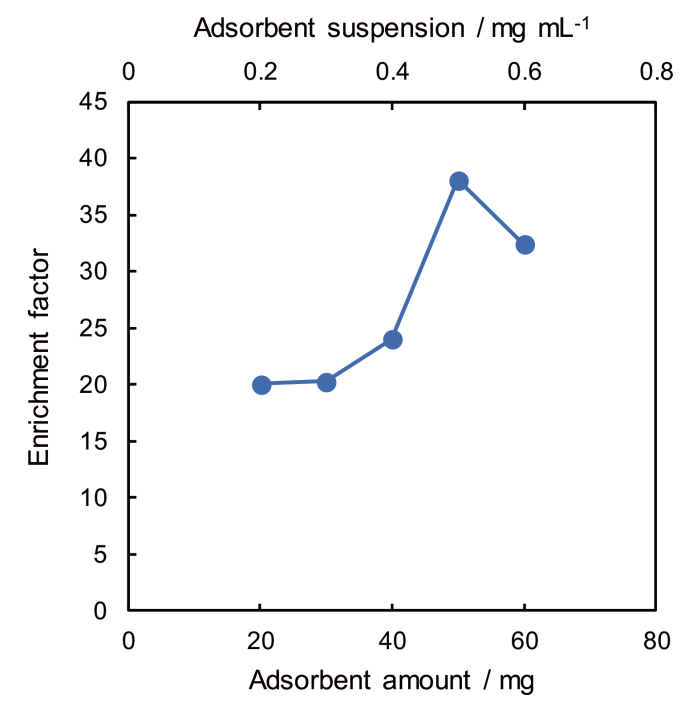

Fig. 3 Effect of the adsorbent amount on the enrichment factor of Rh. Sample, Rh $1 \mathrm{ng} \mathrm{mL}^{-1}$ (100 mL); solution $\mathrm{pH}, 5$; eluent, $\mathrm{HCl}$ $0.5 \mathrm{~mol} \mathrm{~L}^{-1}(1 \mathrm{~mL})$.

sites of magnetic kaolin. Hence, in light of the results, the solution $\mathrm{pH} 5.0$ was chosen as the optimum condition.

\section{Effect of the eluent}

The influence of the type of eluent on the Rh enrichment factor was investigated. As can been seen in Fig. 1, the adsorption of $\mathrm{Rh}$ onto the magnetic kaolin at $\mathrm{pH} 3$ was relatively low, which means that desorption in acidic media can be useful for the magnetic kaolin adsorbent. Therefore, a variety of acid solutions were tested as eluents, as shown in Fig. 2. From the results elution with a concentration of $0.5 \mathrm{~mol} \mathrm{~L}^{-1} \mathrm{HCl}$ gave the maximum factors. Hence, $1 \mathrm{~mL}$ of $0.5 \mathrm{~mol} \mathrm{~L}^{-1} \mathrm{HCl}$ eluent was selected for the elution conditions.

\section{Effect of the adsorbent amount}

In the solid extraction (adsorption onto the solid), the amount (suspension concentration) of magnetic adsorbent becomes one of the main factors effecting on the extraction of analytes. Therefore, the effect of the suspension concentration of magnetic kaolin on the $\mathrm{Rh}$ enrichment factor was evaluated in the range of 0.2 to $0.5 \mathrm{mg} \mathrm{mL}^{-1}$, as illustrated in Fig. 3. The enrichment factor for $\mathrm{Rh}$ increased with an increase in the adsorbent. This fact could be caused by the availability of a greater sorption situation and a larger surface area. At over a value of $0.5 \mathrm{mg} \mathrm{mL}^{-1}$, the factor of $\mathrm{Rh}$ decreased. Consequently, a suspension concentration of $0.5 \mathrm{mg} \mathrm{mL}^{-1}$ was selected as the optimum magnetic kaolin content for subsequent experiments.

\section{Interferences}

Interferences from the coexisting elements have been described for the determination of rhodium by ETAAS. ${ }^{3,4,12}$ Therefore, the effects of $\mathrm{Ca}, \mathrm{Cu}, \mathrm{K}, \mathrm{Mg}, \mathrm{Mn}, \mathrm{Ni}$ and $\mathrm{Pb}$, which are generally present as matrix elements in environmental water, on the enrichment factors for $\mathrm{Rh}$ were investigated. The concentration of the matrix elements was $10^{3}$-times larger relative to that of Rh. The results are shown in Fig. 4. Most of the matrix elements could not interfere with the enrichment factor of Rh. It was reported in a previous paper ${ }^{12}$ that interferences by matrix elements for Rh could be associated with the adsorption power of the elements. Therefore, the interference for $\mathrm{Rh}$ was tried to

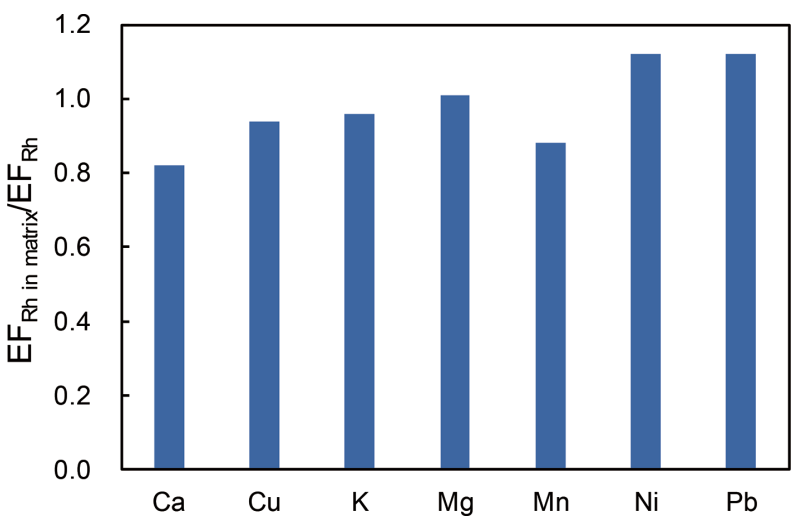

Fig. 4 Effect of matrix elements on the enrichment factor of Rh. Sample, Rh $1 \mathrm{ng} \mathrm{mL} \mathrm{L}^{-1}(100 \mathrm{~mL})$; matrix elements, $1 \mu \mathrm{g} \mathrm{mL}^{-1}$; solution $\mathrm{pH}$, 5; adsorbent, magnetite/kaolin $50 \mathrm{mg}$; eluent, $\mathrm{HCl} 0.5 \mathrm{~mol} \mathrm{~L}^{-1}(1 \mathrm{~mL})$.

be evaluated in the base of standard potentials related to the adsorption power. The standard potentials of typical existing ions are as follows: ${ }^{13} E^{0}\left(\mathrm{Rh}^{3+} / \mathrm{Rh}\right)=0.758 \mathrm{~V}, E^{0}\left(\mathrm{Ca}^{2+} / \mathrm{Ca}\right)=$ $2.3419 \mathrm{~V}, E^{0}\left(\mathrm{Cu}^{2+} / \mathrm{Cu}\right)=0.3419 \mathrm{~V}, E^{0}\left(\mathrm{~K}^{+} / \mathrm{K}\right)=2.931 \mathrm{~V}, E^{0}\left(\mathrm{Mg}^{2+} / \mathrm{Mg}\right)$ $=2.372 \mathrm{~V}, E^{0}\left(\mathrm{Mn}^{2+} / \mathrm{Mn}\right)=2.690 \mathrm{~V}, E^{0}\left(\mathrm{Ni}^{2+} / \mathrm{Ni}\right)=0.257 \mathrm{~V}, E^{0}\left(\mathrm{~Pb}^{2+} / \mathrm{Pb}\right)$ $=0.1262 \mathrm{~V}$. From these data, it could be speculated that the adsorption of rhodium may occur predominantly. Therefore, it is reasonable that these tested matrix elements did not interfere with rhodium preconcentration, by considering these data. Since magnetic kaolin preconcentration appears to be relatively interference-free, the method was applied for the determination of $\mathrm{Rh}$ in environmental samples. The mechanism for the preconcentration process may include ion exchange, physical adsorption and the interaction between the element $\mathrm{Rh}$ and the magnetic kaolin surface. From information in the literature, it could not be clarified which process is predominant for the adsorption of $\mathrm{Rh}$ onto magnetic kaolin.

\section{Detection limit, enrichment factor and reproducibility}

The detection limit $(3 S / N)$ of rhodium by the combination of the magnetic kaolin preconcentration and ETAAS was $16 \mathrm{pg} \mathrm{mL}^{-1}$ under the optimum conditions. The value was better, compared with the detection limits with ICP-OES $\left(8 \mathrm{ng} \mathrm{mL}^{-1}\right)^{14}$ and the combination of the cloud point extraction and ETAAS $\left(23 \mathrm{pg} \mathrm{mL}^{-1}\right)^{3}$. The enrichment factor was 38 . Also, the reproducibility for the ETAAS with the combination of the magnetic kaolin preconcentration was investigated. The relative standard deviation (RSD) in the case of $1.0 \mathrm{ng} \mathrm{mL}^{-1}$ only was $5.7 \%$ for eight measurements.

\section{Determination of rhodium in environmental samples}

The developed preconcentration techniques were applied into the environmental samples (rain and mineral water). Environmental samples spiked with $1.0 \mathrm{ng} \mathrm{mL}^{-1}$ were determined by GFAAS after the preconcentration method. Under the optimum conditions, the dynamic range for the calibration curve fabricated from the standard $\mathrm{Rh}$ solution was up to $3 \mathrm{ng} \mathrm{mL}^{-1}$. Table 1 gives the determination results obtained for environmental samples. The recovery value from rhodium spiked water samples was in the range of 100 to $121 \%$. The RSD (relative standard deviation) for the spiked samples were better than $6 \%$ for three replicate analyses. It was noted from the analytical determination results that the developed preconcentration method was suitable for the determination of trace $\mathrm{Rh}$ in environmental water samples. 
Table 1 Determination of rhodium in water

\begin{tabular}{lccc}
\hline \multirow{2}{*}{ Sample } & \multicolumn{3}{c}{ Concentration of rhodium $/ \mathrm{ng} \mathrm{mL}^{-1}$} \\
\cline { 2 - 4 } & Added & Found & Recovery, \% \\
\hline $\begin{array}{l}\text { Rain water } \\
\text { (Mie, Japan) }\end{array}$ & - & n.d. & - \\
Mineral water & 1.0 & $1.21 \pm 0.07$ & 121 \\
& - & n.d. & - \\
\hline
\end{tabular}

n.d.: not detected. Number of analysis $>3$.

\section{Conclusions}

The magnetic nano composite kaolin- $\mathrm{Fe}_{3} \mathrm{O}_{4}$ was successfully applied into an adsorbent for solid extraction and the preconcentration of $\mathrm{Rh}$. The combination of solid-phase extraction by magnetic kaolin and ETAAS offered a significant analytical performance. The advantages of the present preconcentration methods are easy preparation of the adsorbent, fast extraction, fast magnetic separation, simple, low cost and convenient.

\section{Acknowledgements}

All experiments were conducted at Mie University. The present research was partly supported by a Grant-in-Aid for Scientific Research (C) 18K11709 from the Ministry of Education, Culture, Sports, Science, and Technology of Japan. Any opinions, findings, conclusions, or recommendations expressed in this paper are those of the authors and do not necessarily reflect the view of the supporting organizations.

\section{Supporting Information}

This material is available free of charge on the Web at http:// www.jsac.or.jp/analsci/.

\section{References}

1. C. Almécija, A. Cobelo-García, and J. Santos-Echeandía, Talanta, 2016, 146, 737.

2. J. Rinkovec, P. Gordana, S. Zuzul, and S. Roncevic, Bull. Environ. Contam. Toxicol., 2017, 98, 672.

3. Q. Han, Y. Huo, J. Wu, Y. He, X. Yang, and L. Yang, Molecules, 2017, 22, 487.

4. P. P. Ndibewu, A. Marais, and M. Crindle, "PGMs Preconcentration \& Spectroscopy: Trace/Ultratrace Levels Analysis: Socio-economic importance of PGMs, Chemistry/ Spectroscopy, Adsorption/Preconcentration, Separation/ Determination of PGMs", 2014, LAP LAMBERT Academic Publishing, Latvia.

5. Ö. Yavuz, Y. Altunkaynak, and F. Güzel, Water Res., 2003, 37, 948.

6. L. Qin, L. Yan, J. Chen, T. Liu, H. Yu, and B. Du, Ind. Eng. Chem. Res., 2016, 55, 7344.

7. P. Zong, S. Wang, and C. He, Water Sci. Technol., 2013, 67, 1642.

8. M. Amjadi, A. Samadi, and J. L. Manzoori, Microchim. Acta, 2015, 182, 1627.

9. S. Kaneco, K. Hayashi, H. Katsumata, and T. Suzuki, Int. J. Environ. Anal. Chem., 2013, 93, 1381,

10. M. Furukawa, I. Tateishi, H. Katsumata, and S. Kaneco, ChemEngineering, 2019, 3, 67.

11. T. Kusutaki, M. Furukawa, I. Tateishi, H. Katsumata, and S. Kaneco, ChemEngineering, 2019, 3, 74.

12. S. Kaneco, J. Ogawa, K. Ohta, S. Itoh, and T. Mizuno, Talanta, 1998, 46, 139.

13. D. R. Lide (ed.), "Handbook of Chemistry and Physics", 85th ed., 2004, CRC Press, Boca Raton, FL, 8 - 23.

14. K. Sawada (ed.), "Wakate Kenkyusya Notameno Kikibunseki Labogaido (A Laboratory Guide to Instrumental Analysis for Young Chemists, in Japanese)", 2006, Kodansha Scientific, Tokyo, 151. 